\title{
RESPONSABILIDAD POR INSOLVENCIA EN LOS GRUPOS EMPRESARIALES. UNA APROXIMACIÓN A LA TEORÍA DEL ADMINISTRADOR DE HECHO EN EL DERECHO CHILENO*
}

\author{
RESPONSIBILITY FOR INSOLVENCY IN THE COMPANIES GROUPS. \\ AN APPROXIMATION TO THE THEORY OF THE ADMINISTRATOR OF \\ FACT IN THE CHILEAN LAW
}

\author{
EDUARDO JeQUiER LEHUEDÉ ${ }^{* *}$
}

\begin{abstract}
RESUMEN: El presente trabajo indaga sobre la situación actual del derecho chileno en materia de responsabilidad civil de la sociedad controladora de un grupo empresarial, por la insolvencia de una sociedad dominada. Se analizan para ello los principales sistemas implementados en el derecho comparado; la nueva regulación que trae sobre este punto la Ley $\mathrm{N}^{\circ}$ 20.720, sobre "Reorganización y Liquidación de Empresas y Personas"; y se plantea la conveniencia de incluir en sus disposiciones la figura del administrador de hecho y una acción directa en su contra, como eventual responsable del déficit concursal.
\end{abstract}

Palabras clave: Administrador de hecho, sociedad dominante, grupo empresarial, responsabilidad civil, insolvencia, sociedad dominada, déficit concursal.

ABSTRACT: The present survey deals with the current situation of Chilean law on civil liability of the controller of a corporate group, by the insolvency of a dominated society. They are analyzed for the main systems deployed in the comparative law; the new regulation of the Law No. 20.720, about "Reorganization and liquidation of companies and persons"; and it is proposed to include in its provisions the figure of the de facto administrator and a direct action against this figure as an eventual responsible for the bankruptcy situation.

Key words: Fact Administrator, dominant company, corporate group, civil responsibility, insolvency, dominated company, bankruptcy deficit.

\section{INTRODUCCIÓN}

Con fecha 9 de enero de 2014 se publicó en el Diario Oficial la Ley $N^{\circ} 20.720$, que "Sustituye el régimen concursal vigente por una ley de Reorganización y Liquidación de empresas y personas, y perfecciona el rol de la Superintendencia del ramo" -en adelante la LRL-. Como se desprende del orden propuesto ya en su título, la ley opta precisamente por un Derecho concursal que privilegia los mecanismos para concursales y preventivos de

\footnotetext{
El presente estudio se ha realizado como parte del Proyecto FONDECYT Iniciación año 2012, N¹1121226, titulado "Quiebra e insolvencia en los grupos empresariales. Aproximación hacia supuestos de responsabilidad desde la perspectiva de la teoría del administrador de hecho”, del cual el autor es investigador responsable.

** Doctor en Derecho, Universidad de Valencia, España. Mg. en Derecho de la Empresa, Pontificia Universidad Católica de Chile. Profesor de Derecho Comercial, Universidad de los Andes (Mons. Álvaro del Portillo 12455, Las Condes, Santiago de Chile).
} 
JEQUier LeHUEDÉ, Eduardo — "Responsabilidad por insolvencia en los grupos empresariales..."

solución del fenómeno de la insolvencia empresarial, relegando así su vertiente liquidatoria a un plano residual o subsidiario que apunta, como lo destacó en su momento el mensaje presidencial, a la conservación de la empresa como unidad productiva ${ }^{1}$.

El Estado chileno abandona así la visión que mostró por décadas respecto del fenómeno de la insolvencia y de su tratamiento concursal, reflejada en un sistema normativo esencialmente neutral de cara a los diversos intereses involucrados en el complejo falencial. Pese a las modificaciones introducidas en el año 2005 por las leyes $\mathrm{N}^{\circ} 20.004$ y $\mathrm{N}^{\circ} 20.073$, tendientes a perfeccionar -entre otros aspectos- el mecanismo de los convenios judiciales como alternativa a la quiebra, la Ley $\mathrm{N}^{\circ} 18.715$, sobre Quiebras -LQ- (D.O. de 28 de octubre de 1982$)^{2}$, opta -en efecto- por ceder la iniciativa a la interacción regulada de los intereses antes mencionados, que conforman la comunidad de pérdidas, sin interferir en la orientación que tomará finalmente el concurso ni manifestar preferencias por uno u otro camino, de convenio o de quiebra.

En lo que concierne concretamente a la responsabilidad por la insolvencia de las sociedades integrantes a un grupo empresarial, la nueva ley da un paso importante en comparación a la LQ que se deroga, al incorporar la figura de la postergación de los créditos de las sociedades relacionadas y un nuevo tipo penal, que recoge implícitamente la figura del administrador de hecho. Tal avance, sin embargo, aunque destacable, constituye una medida indirecta y por ende insuficiente para hacer efectiva la responsabilidad civil de la sociedad matriz por la insolvencia de la dominada, pues en este punto la ley sigue considerando la insolvencia de las personas jurídicas como un fenómeno subjetivamente aislado o de "sociedades-isla", propio de cada ente deudor individualmente considerado.

La Ley $\mathrm{N}^{\circ}$ 20.720, por lo mismo, no aborda el tratamiento de la insolvencia en un esquema societario complejo e integrado, como es el de los grupos empresariales, lo que implica reconocer únicamente la diversidad más no la unidad ni la particular comunión de relaciones intersocietarias que genera una estructura de grupo ${ }^{3}$.

Por lo anterior, y partiendo de los postulados de la teoría del administrador de hecho, consagrada en diversos ordenamientos comparados ${ }^{4}$, pretendemos introducirnos en

\footnotetext{
1 Según el Mensaje Presidencial, el Proyecto de Ley enviado al Congreso se basó fundamentalmente en la idea de "fomentar o estimular, en primer lugar, la reorganización efectiva de empresas viables, es decir, permitir que un emprendimiento dotado de posibilidades de subsistir y prosperar pueda superar las dificultades transitorias en que se encuentra, con ayuda de sus acreedores y con miras a permanecer como unidad productiva en el tiempo. Asimismo, y en segundo lugar, es también deber del Estado entregar las herramientas idóneas para asegurar que aquellos emprendimientos que simplemente carezcan de la entidad necesaria para perseverar puedan ser liquidados en breve tiempo, estimulando el resurgimiento del emprendedor a través de nuevas iniciativas" (Mensaje Presidencial, de 15 de mayo de 2013, en Historia de la Ley $N^{\circ} 20.720$, p. 7).

2 La Ley $\mathrm{N}^{\circ} 18.715$, incorporada por la Ley $\mathrm{N}^{\circ} 20.080$ al Libro IV del Código de Comercio, fue derogada por el art. 344 de la Ley $\mathrm{N}^{\circ} 20.720$, sin perjuicio de lo dispuesto en el número 20) del artículo 347, que deroga a su vez el Libro IV del Código referido, y en los artículos primero y duodécimo transitorios de la misma ley. La entrada en vigencia de esta última se fijó en nueve meses después de su publicación en el Diario Oficial, salvo las disposiciones contenidas en el Capítulo IX y la norma del artículo 344 recién citada, las que se ajustarán a lo dispuesto en el numeral 8 del artículo tercero transitorio de la ley.

3 Antunes (1994) pp. 381-383.

4 Así por ejemplo, la Ley Concursal de Uruguay, Nº18.387 de 2008, incorpora explícitamente la figura del administrador de hecho en sus arts. 112, 192 y 248. Lo propio ocurre en la Ley Concursal española (22/2003, de
} 
la dinámica propia y característica de los grupos empresariales, para dilucidar en definitiva el tratamiento que debe darse a un aspecto de la mayor relevancia y que no ha sido abordado sin embargo de manera suficiente en nuestro medio. En concreto, y tratándose de la responsabilidad de los administradores de hecho, la investigación planteada se orienta a determinar la relación que existe entre el estado judicial de liquidación de una sociedad dominada y la necesaria incidencia operativa y de gestión que sobre ella ha ejercido la sociedad dominante, en cuanto administrador de hecho del grupo. En otros términos, se busca responder aquí las siguientes interrogantes:

a) ¿Debe hacerse extensiva la quiebra (liquidación forzosa) de la sociedad dominada a la sociedad dominante como administradora de hecho?

b) Alternativamente; ¿debe establecerse un régimen de responsabilidad civil o patrimonial que afecte únicamente a los administradores que han dirigido de hecho los negocios del fallido, provocando o agravando su estado de cesación de pagos? ${ }^{6}$

c) ¿Debe establecerse algún mecanismo legal diferenciado de responsabilidad del administrador de la sociedad dominada en quiebra (liquidación), que ha actuado bajo instrucciones y por imposición de la dominante?7 $\mathrm{O}$ planteado de otra forma; ¿Supone la extensión de responsabilidad al administrador de hecho una exoneración correlativa de responsabilidad del administrador de derecho por la insolvencia judicialmente declarada de la sociedad dominada?

\section{RESPONSABILIDAD POR INSOLVENCIA EN UN ESQUEMA DE SOCIEDADES INTEGRADAS A UN GRUPO EMPRESARIAL. ESTADO DE LA CUESTIÓN EN EL DERECHO CHILENO}

A los grupos empresariales, sus tipos y a la figura de la sociedad matriz como administrador de hecho de las sociedades integradas al grupo nos hemos referido ya en otra oportu-

17 de julio), que reconoce también la señalada figura en los arts. 93.2.2, 164.1, 172.2 y 172.3, entre otras; y en la Ley de Sociedades de Capital (Real Decreto Legislativo 1/2010, de 2 de julio), arts. 231.2.b y 236.

5 Esta es la solución del C. de Com. francés, art. L.652-1, que hace responsable de las deudas de la sociedad insolvente a los "dirigentes de hecho o de derecho (...) cuando quede establecido que dicho dirigente ha contribuido al estado de insolvencia..." [Cfr. Miguens (2000)]. La misma tendencia sigue el art. 147.1 de la ley concursal italiana. Por su parte, el art. 87 del Proyecto de Novena Directiva del Consejo de la CEE (Documento III/1.639/84) hace responsable directa e ilimitadamente a la sociedad dominante por las deudas de la dominada, de manera automática aunque en subsidio de una demanda en contra de esta última, siempre y cuando dicha insolvencia no sea consecuencia de la dirección unitaria de la primera. La iniciativa fracasó sin embargo, por la reticencia de los Estados miembros a modificar en este sentido sus legislaciones internas, y por la rigidez del modelo que se proponía, considerando que la responsabilidad de las sociedades agrupadas no puede ser asignada con un criterio directo, estructural o "global" como dice LuTTER [LUTTER (1997) p. 239] derivado de la sola relación de dominio o dirección unitaria, sino solo cuando concurren ciertas circunstancias adicionales.

6 En el derecho europeo, países como Alemania y Reino Unido han evitado extender los efectos patrimoniales de la quiebra de la sociedad dominada a la dominante, optando por un régimen de responsabilidad que se circunscribe a los administradores de hecho que han contribuido a la situación de insolvencia declarada.

7 En este sentido, y como se dirá en el texto, Sánchez Calero propone un tratamiento diferenciado de la responsabilidad de los administradores de derecho de la sociedad dominada, cuando son obligados a actuar en determinada forma por el administrador de hecho [SÁNCHEZ CALERO (1991) p. 933]. 
nidad, a cuyas conclusiones nos remitimos como punto de partida del presente trabajo ${ }^{8}$. Con esa base, en lo que sigue nos proponemos explorar los mecanismos y criterios que a nuestro juicio debiesen incorporarse en el sistema concursal chileno para hacer efectiva la responsabilidad civil de la sociedad dominante y sus administradores de derecho, por la insolvencia de las sociedades dominadas integradas al grupo. Para ello, revisaremos brevemente el estado de la cuestión en el derecho interno -que como ya se adelantó poco ofrece en este sentido- para luego analizar en forma crítica las dos principales herramientas que con algunos matices se han implementado en el derecho comparado para abordar esta materia: la extensión de la quiebra (o liquidación de activos) y la recién mencionada figura del administrador de hecho.

\section{Estado de la cuestión en el Derecho CONCURSAl Chileno: la Ley N ${ }^{\circ} 20.720$}

En Chile no existen normas legales diseñadas para cautelar el interés minoritario ni el de los acreedores en el marco de los grupos societarios; o al menos no un estatuto normativo particular, distinto de aquel aplicable en un esquema de sociedades-isla9 ${ }^{9}$ La Ley $\mathrm{N}^{\circ}$ 20.720, con todo, da un paso destacable aunque apenas insipiente en la tutela de los derechos de los acreedores de sociedades insolventes integradas a un grupo, como nos proponemos demostrar a continuación.

\subsection{La figura de la postergación de los créditos relacionados}

La concepción de la insolvencia como fenómeno de sociedades-isla (entity law), que recoge la actual LQ, implica que frente a la quiebra de alguna de las sociedades integradas a un grupo las restantes, matriz o dominadas, reciben el mismo tratamiento que cualquier otro acreedor; con algunas excepciones aisladas, claro está, pero referidas básicamente al cómputo del pasivo con derecho a voto en determinadas ocasiones (art. 177 bis y 190 de la LQ). Dicha circunstancia, a su vez, genera el contrasentido de que la sociedad dominante, pese a ser muchas veces la causante de la insolvencia de la filial, puede transformarse eventualmente en la controladora del proceso concursal en la medida que sea ella la principal acreedora de la filial fallida, directamente y/o a través de las demás sociedades del grupo. Todavía más, ese camino puede ser provocado incluso por la matriz, como estrategia de grupo y como una medida financiera más atractiva que la inyección de recursos frescos que solucionen la insolvencia provocada de la filial. Como se dijo supra, la LRL da un paso relevante en este sentido, al incorporar la figura de la posposición de los créditos de acreedores relacionados con la concursada hasta que los restantes créditos - los no relacionados- se hayan pagado íntegramente ${ }^{10}$. El art. 63 de la LRL, a propósito del procedimiento de reorganización judicial, señala en este punto que salvo los casos de excepción que la misma disposición contempla (artículos 72, 73 y 74 de la LRL), los créditos de aquellos acreedores

\footnotetext{
8 JEQUier (2014) pp. 121-152.

9 PugA, reconociendo este mismo déficit, destaca como única situación especial regulada por la ley aquella contemplada en el art. 71 bis de la LSA, referida al derecho de retiro del accionista minoritario cuando un controlador adquiera más del 95\% de las acciones de una SA abierta. En lo demás, plantea la necesidad de recurrir a los mecanismos de protección contemplados en el derecho común. PUGA (2011) p. 669 y ss.

10 Al concepto de acreedores "Personas Relacionadas" se refiere el art. 2 N²6 de la LRL, que amplía incluso la noción que de ellos se da en el art. 100 de la LMV.
} 
relacionados con el deudor, cuyos créditos no se encuentren debidamente documentados 90 días antes del inicio del procedimiento de reorganización, quedarán pospuestos y se pagarán por ende después de todos los restantes. Lo mismo se aplicará -agrega la normarespecto de aquellos acreedores relacionados cuyos créditos se encuentren debidamente documentados en el plazo señalado, siempre y cuando (i) la propuesta de Acuerdo los incluya expresamente y (ii) el veedor haya informado favorable y fundadamente respecto de tal inclusión, en forma previa.Por su parte, y tratándose ahora del procedimiento de liquidación de activos, el art. 241 inc. final de la misma ley reitera el criterio anterior y su excepción, referida como se dijo a la previa y oportuna documentación de los créditos respectivos.

Por esta vía entonces, conocida ya por el derecho español ${ }^{11}$ y en el sistema alemán ${ }^{12}$, la ley chilena se hace cargo de un fenómeno que hasta aquí había pasado prácticamente inadvertido para el legislador concursal, generando con ello grandes dificultades al momento de definir la composición del pasivo concursable y la participación de los acreedores relacionados en la liquidación del activo de la quiebra. La LQ, a lo más, abordaba el punto al regular la determinación del pasivo con derecho a voto en los convenios judiciales preventivos (art. 177 bis, art. 177 ter y art. 190), pero en ningún caso llegaba a posponer el pago de los créditos relacionados, como hace ahora la Ley $\mathrm{N}^{\circ} 20.720$.

Sin embargo, la innovación que introduce en este sentido la LRL ha sido tímida y por lo mismo insuficiente, pues si bien aborda el fenómeno descrito, los alcances de la fórmula que utiliza para ello resultan muy limitados. El ámbito material y subjetivo en que opera esta posposición crediticia, en efecto, se circunscribe únicamente al patrimonio del deudor insolvente que ha contratado con el acreedor respectivo, lo que implica que el acceso al patrimonio de la sociedad dominante del grupo y/o al de sus administradores de derecho, que ha(n) provocado -en la hipótesis que aquí interesa- la situación de insolvencia de la dominada, sigue estando cerrado para los acreedores de la primera. Todavía más, en estos casos la postergación de los créditos relacionados constituirá por lo general un costo perfectamente previsible y eventualmente marginal para la controladora del grupo, cuyo impacto

11 Es el sistema contemplado en la legislación concursal del año 2003, en España, que trata precisamente de los créditos subordinados. Según el art. 92.5 de la ley concursal española, N²2/2003 de 9 de julio, "Son créditos subordinados (...): 5. ${ }^{\circ}$ Los créditos de que fuera titular alguna de las personas especialmente relacionadas con el deudor a las que se refiere el artículo siguiente, excepto los comprendidos en el artículo 91.1. ${ }^{\circ}$ cuando el deudor sea persona natural y los créditos diferentes de los préstamos o actos con análoga finalidad de los que sean titulares los socios a los que se refiere el artículo 93.2.1..$^{\circ}$ y 3. ${ }^{\circ}$ que reúnan las condiciones de participación en el capital que allí se indican". A su vez, la ley considera que una persona se encuentra "especialmente relacionada con el deudor" si se trata -entre otros casos- de "sociedades que formen parte del mismo grupo que la sociedad declarada en concurso y sus socios" (art. $93 \mathrm{~N}^{\circ} 2.3$ ). Cosa similar hace entonces la Ley $\mathrm{N}^{\circ} 20.720$, al remitirse para estos efectos al art. 100 de la Ley de Mercado de Valores -LMV-, según se dirá en el texto.

12 En el sistema alemán, es doctrina y jurisprudencia asentada que los socios -y las demás sociedades del grupono están obligados a contribuir a la superación de la situación de insolvencia; pero si lo hacen no debe ser con recursos de terceros, sino con recursos propios. Si no lo hacen en cambio, deberán enfrentar las consecuencias de la subordinación de sus créditos en la quiebra, que tendrán por lo mismo un carácter residual. Por esta vía de subordinación, entonces, desaparece por una parte el incentivo de "provocar" la quiebra de la sociedad dominada, como alternativa a su capitalización, a lo que se suma que el momentum de la declaración de quiebra -y por ende su eficacia como herramienta concursal- no dependerá necesariamente de la decisión de la sociedad dominante, forjada como se dijo con miras al favorecimiento de sus propios intereses, pues las expectativas de manejar el concurso y de pagarse dentro de él serán ahora residuales. 
JeQUier LehUEDÉ, Eduardo — "Responsabilidad por insolvencia en los grupos empresariales..."

patrimonial habrá sido considerado, cuantificado y aceptado incluso por la misma como una variable más al momento de evaluar la alternativa del concurso de la sociedad dominada en insolvencia, vs. la inyección de capital fresco.

\subsection{La nueva figura del artículo 463 quáter del Código Penal}

Otra importante novedad que trae la nueva legislación concursal consiste en sancionar como autor del delito contemplado en el art. 463 quáter nuevo del Código Penal, a aquella persona que, teniendo la dirección o administración de los negocios del deudor que es sometido luego al procedimiento de declaración de activos, hubiere incurrido en cualquiera de las conductas a que se refieren a su turno los artículos 463, 463 bis y 463 ter nuevos del mismo código, introducidos también por el art. 345 de la Ley N²0.720 Señala concretamente esta norma: "Artículo 463 quáter. Será castigado como autor de los delitos contemplados en los artículos 463, 463 bis y 463 ter quien, en la dirección o administración de los negocios del deudor, sometido a un procedimiento concursal de reorganización o de liquidación, hubiese ejecutado alguno de los actos o incurrido en alguna de las omisiones allí señalados, o hubiese autorizado expresamente dichos actos u omisiones”.

En su texto original, enviado al Congreso Nacional por el Presidente de la República, el actual art. 463 quáter señalaba en cambio lo siguiente: "Artículo 463 C: Los gerentes, directores, administradores de hecho o de derecho, factores o representantes del deudor respecto del cual se hubiere iniciado un procedimiento concursal de reorganización o de liquidación, serán castigados como autores de los delitos contemplados en los artículos 463, 463 A y 463 B anteriores, si en la dirección de los negocios del deudor y con conocimiento de la situación de estos, hubieren ejecutado en perjuicio de sus acreedores, alguno de los actos o incurrido en alguna de las omisiones allí señaladas, o hayan inducido o forzado a otro a hacerlo, o cuando hubieren autorizado expresamente dichos actos u omisiones"13.

Tras algunas modificaciones menores, durante el segundo trámite constitucional la norma fue reemplazada por la actual y definitiva, siguiéndose aquí sugerencias que fueron acogidas sin cuestionamiento por la Comisión de Constitución de la Cámara de Diputados: "El profesor señor [Héctor] Hernández manifestó sus dudas en torno a si se desea restringir formalmente el círculo de sujetos que pueden ser equiparados al deudor o, por el contrario, se quiere equiparar a este a cualquiera que en los hechos dirija sus negocios. Si es lo primero, y en el evento de que por "administrador de hecho" se entienda, como lo hace un sector de la doctrina española, aquel que tiene poder con un defecto formal, sería conveniente una fórmula genérica que aluda a la representación del deudor, como por ejemplo, "quienes actúan en nombre del deudor". Si es lo segundo, lo único razonable es prescindir de la serie de cargos y limitarse a señalar que se aplicarán las penas previstas para el deudor "a quien, en la dirección de los negocios del deudor y con conocimiento de la situación de estos, hubieren ejecutado alguno de los actos o incurrido en alguna de las omisiones allí se-

13 Segundo Informe de las Comisiones de Constitución, Legislación, Justicia y Reglamento y Economía, Unidas, de 9 de abril de 2013, en Historia de la Ley $N^{\circ}$ 20.720, Biblioteca del Congreso Nacional, p. 137. 
ñalados, o hubieren autorizado expresamente dichos actos u omisiones". Hizo notar que el texto del Senado encierra una ambigüedad que cabría despejar" ${ }^{\text {"14 }}$.

Tales observaciones fueron recogidas como se dijo durante el señalado trámite legislativo, eliminándose errada e innecesariamente la referencia al administrador de hecho que contenía el texto original ${ }^{15}$. Su reemplazo por el texto definitivo, a fin de cuentas, no hizo más que generar confusión en donde no la había y obliga por lo mismo a indagar en la historia de la ley para descubrir el verdadero sentido de la misma, que claramente incluye la figura del administrador de hecho en su concepción amplia.

Con todo, y pese a la novedad de la norma, su eficacia como herramienta para hacer efectiva la responsabilidad del administrador de hecho nos parece muy limitada si se la incardina en la dinámica de los grupos empresariales, lo que se desprende de tres aspectos básicos:

a) Primero, porque la responsabilidad penal es esencialmente personal y no alcanza en estas materias a las personas jurídicas ${ }^{16}$. Por esta vía y en el marco del proceso penal, por ende, ni siquiera resultará posible hacer efectiva la responsabilidad civil de la sociedad dominante, como administradora de hecho del grupo, pues esta jamás podrá considerarse como sujeto activo del delito referido.

b) Además, porque toda la LRL se ha construido bajo un esquema de sociedadesisla ${ }^{17}$, de manera que resulta a lo menos dudoso entender que el nuevo tipo penal pueda hacerse extensivo a los administradores de derecho de la sociedad matriz que actúa como administradora de hecho de la filial insolvente.

c) Por último, porque la eficacia de esta nueva herramienta depende de la necesaria concurrencia y prueba del dolo penal - no civil- y de la existencia previa de un procedimiento de liquidación de activos, contemplada en el art. 463 quáter como una condición objetiva de punibilidad.

\footnotetext{
14 Informe de la Comisión de Constitución, Cámara de Diputados, Segundo Trámite Constitucional, en Historia de la Ley $N^{\circ} 20.720$, pp. 2278 y 2279.

15 La eliminación fue injustificada por cuanto, a diferencia de lo que se sostuvo en la sesión respectiva, en el derecho español -y en el derecho comparado en general- la concepción formalista o restringida del administrador de hecho (o administrador aparente o notorio) se encuentra ya superada por una concepción amplia y funcional del administrador de hecho (o administrador oculto o en las sombras), fruto principalmente de la labor doctrinal y jurisprudencial en Italia (vid. BonelLi [1985] p. 259) y recogida por prácticamente todas las legislaciones europeas, que atienden únicamente a las funciones administrativas de facto que realiza efectivamente el sujeto sin importar si este ha sido nombrado o no como tal administrador. Se trata, incluso, de una tesis anterior a la incorporación de la figura del administrador de hecho al Derecho concursal español, que alguna doctrina minoritaria mantiene sin embargo hasta hoy [por todos, MOYA JIMÉNEZ (2012) pp. 108 y 109].

$16 \mathrm{El}$ art. $1^{\circ}$ de la Ley $\mathrm{N}^{\circ} 20.393$ no contempla ninguno de los delitos que introduce la Ley $\mathrm{N}^{\circ} 20.720$.

17 Así por ejemplo, ni el art. 56 ni el art. 115 de la LRL exigen que la empresa deudora que se somete a los procedimientos de reorganización o de liquidación -respectivamente- presente balances consolidados o que informe sobre su pertenencia a un grupo empresarial, como sí lo hacen por ejemplo los arts. 6.2.2 y 6.3.4 de la ley concursal española de 2003. Esa sola circunstancia sitúa a las restantes sociedades del grupo -y principalmente a la matriz- en los extramuros del proceso concursal, con la sola excepción de la figura de la posposición de créditos (art. 63 LRL). Tampoco se contempla la posibilidad de declarar concursos conjuntos o de acumular los concursos de sociedades integradas a un mismo grupo, a que se refieren los arts. 3 y 25 de la Ley concursal española de 2003.
} 
Por lo anterior, echamos en menos en la LRL un expreso reconocimiento de la figura del administrador de hecho -como ocurre precisamente en la ley concursal española, según se dirá infra- en cuanto sujeto civilmente responsable frente a los acreedores de la sociedad dominada insolvente. Sobre esto volveremos más adelante.

\section{GRUPOS DE SOCIEDADES Y SISTEMAS DE RESPONSABILIDAD POR INSOLVENCIA DE LA SOCIEDAD DOMINADA EN EL DERECHO COMPARADO. BREVE REVISIÓN}

Una característica principal de los grupos empresariales radica en la relación dialéctica e indisoluble que se genera entre la autonomía societaria y el control, que aquellos actúan y objetivan. Tal esquema impone, por su particularidad, la compleja tarea de definir un estatuto jurídico de responsabilidad que contemple ambos aspectos y que concilie adicionalmente - por un lado- la responsabilidad por las directrices dañosas dadas por el controlador y -por el otro- la gestión empresarial eficiente del grupo; o como dice TeUbneR ${ }^{18}$, que permita vincular la responsabilidad con el poder real de toma de decisiones de un grupo, de manera que el sistema de imputación de responsabilidad sea "flexible e híbrido".

\section{UNA CUESTIÓN PREVIA: SUPUESTOS GENERALES DE RESPONSABILIDAD DE LA SOCIEDAD} MATRIZ POR LA INSOLVENCIA DE LA DOMINADA.

Un primer aspecto a considerar en el análisis sobre la responsabilidad de la matriz y/o de sus administradores de derecho por la insolvencia de la sociedad filial, consiste en determinar si dicho estado patrimonial ha sido el resultado de un proceso autónomo de toma de decisiones de la sociedad dominada o si, por el contrario, este último ha estado sometido a la autoridad decisoria de la sociedad dominante.

En este sentido, la doctrina especializada ha planteado distintas hipótesis de responsabilidad intragrupal, las que pueden resumirse de la manera siguiente:

a) Como regla general, la sociedad dominante debe responder solo cuando se trata de instrucciones dadas por la primera para que la controlada lleve a cabo un negocio jurídico que la perjudique, o para abstenerse de uno que la favorezca. En otros términos, el ejercicio del control de la matriz debe llevar a concluir que, en definitiva, el acto lesivo fue generado por esta última y no por la dominada, en el entendido que ha sido la voluntad de aquella la que se ha manifestado finalmente.

El análisis, por lo mismo, debe ser cuidadoso y caso a caso, pues no toda directriz que cause una merma patrimonial a la dominada será necesariamente cuestionable ${ }^{19}$

\footnotetext{
18 Teubner (1991) p. 198.

19 Un ejemplo extremo de este planteamiento se encuentra en la LSA alemana, que legitima expresamente las instrucciones perjudiciales de la dominante en el caso de los grupos contractuales. El art. 308.1 de la la $A k t G$, en efecto, establece que "Vigente un contrato de dominación, la empresa dominante tiene derecho a impartir instrucciones a la Dirección de la sociedad en lo relativo a la administración de la misma. Si el contrato no establece otra cosa, se pueden impartir, también, instrucciones perjudiciales para la sociedad, cuando sirvan a los intereses de la empresa dominante o de las empresas unidas en grupo con ella y con la sociedad” [EMBID IRUJO
} 
( $v$. $g r$. las pérdidas que resultan del riesgo razonable y propio de toda operación comercial), ni la sola presencia del control permite neutralizar per se el principio de la incomunicabilidad de la responsabilidad entre las sociedades integradas. Para ello hay que atender cuidadosamente a cada situación concreta, sin olvidar el margen de actuación que la dominante tiene sobre la subsidiaria y la autonomía que a esta última le queda. De esta forma, es posible atribuirle responsabilidad a quien verdaderamente actúe o determine el modo de actuar ${ }^{20}$.

b) No basta con imputar la acción a la sociedad dominante, sino que tal acción debe ser calificada como contraria a derecho, capaz de provocar un perjuicio a la dominada, sus socios o acreedores. De esta forma la responsabilidad en materia de grupos se fundamenta en atención a la conducta de los sujetos (responsabilidad por conducta), y no porque estos hayan decidido articular su actividad mediante una estructura de grupo (responsabilidad estructural) ${ }^{21}$. La pauta de conducta a la que se deberá ceñir la dominante será la de una "diligencia profesional propia de la política empresarial unificada”. La prueba de esta diligencia podrá realizarse mediante una pericia técnica brindada por empresarios con vasta trayectoria en grupos empresariales o escuelas superiores de negocios especializadas en cuestiones de grupos de sociedades y para el caso concreto de que se trate ${ }^{22}$.

c) Es a cargo de la dominante el producir prueba de si tales decisiones negociales han sido tomadas autónomamente por la dependiente. En caso de no poder probarlo, aún podrá salvar su responsabilidad probando que su conducta fue la adecuada, esto es, que cumplió con la diligencia debida.

\section{MeCANismos legales alternativos de ReSPONSABILIDAD POR INSOlVENCIA EN LOS} GRUPOS EMPRESARIALES. BREVE SÍNTESIS DEL DERECHO COMPARADO

Hemos dicho supra que la complejidad y diversidad del grupo empresarial, como fenómeno jurídico-económico reconocido por el legislador nacional, genera una serie de dificultades y situaciones particulares que, como tales, no pueden ser abordadas cabalmente en el marco de un derecho tradicional aplicable a las sociedades-isla. Tratándose concretamente de la responsabilidad, el desafío radica por ende en buscar el equilibrio que mencionábamos también, entre responsabilidad por las directrices perjudiciales que se imparten

(2010) p. 183]. En el caso de los grupos de hecho, el art. 311 de la misma ley considera lícitas las instrucciones que resulten perjudiciales para la dominada, en la medida que esos perjuicios sean compensados dentro del mismo ejercicio, o que al menos se garantice dicha compensación. Los arts. 311 al 318, sin embargo, que tratan precisamente de la responsabilidad en los grupos de hecho, son las disposiciones más criticadas y polémicas de la $A k t G$, cuyo origen se explica únicamente por las circunstancias históricas en que se gestaron. En el proyecto original del año 1959, en efecto, se prohibía con carácter general todo perjuicio derivado de instrucciones perjudiciales de la dominante a la sociedad controlada, lo que resultaba perfectamente coherente por lo demás. Sin embargo, y como explica Kübler, tal planteamiento contrataba con una larga práctica societaria en el ámbito de los grupos de sociedades, lo que terminó por flexibilizar radicalmente la idea general, que fue reemplazada como se dijo por la técnica de la compensación de daños [KüBler (2001) p. 612].

20 Girgado (2002) pp. 96-98.

21 Girgado (2002) pp. 99-100.

22 Miguens (1998) p. 389. 
JEQUIER LeHUEDÉ, Eduardo " "Responsabilidad por insolvencia en los grupos empresariales..."

dentro del grupo y la necesaria eficiencia en la dirección unitaria, lo que ha sido -y es- materia de una discusión y análisis legal, doctrinal y jurisprudencial que está lejos de concluir. No se trata, como proponía el proyecto de Novena Directiva de la Comunidad Económica Europea, de establecer un sistema de responsabilidad automática, estructural o global de la sociedad matriz, por el solo hecho de actuar una dirección unitaria en el seno grupal; ni de aferrarse al dogma de la autonomía plena que surge de la personalidad jurídica de las sociedades agrupadas; ni tampoco, en fin, de prescindir por completo de esa personalidad jurídica, mediante técnicas sin contenido sistémico y de resultados impredecibles, como ocurre con la teoría del levantamiento del velo.

Una clara demostración de la complejidad de esta materia -bien surtida de encendidas polémicas doctrinales- es precisamente la diversidad de sistemas y soluciones que se han implementado en el derecho comparado para abordarla; y no solo respecto de las sociedades de grupo, sino también en el ámbito de la responsabilidad de los administradores de derecho de las sociedades insolventes. No es el propósito de esta investigación el adentrarse en un análisis pormenorizado de tales mecanismos, pues ello, amén de pretensioso, escapa a la finalidad y características de la misma. Sin embargo, nos parece relevante referirnos al menos, de manera sucinta, a las distintas soluciones que se han planteado en algunos países que han legislado sobre esta materia, lo que servirá de pauta para decantar nuestra búsqueda en la solución que nos parece más adecuada y eficaz de cara a la normativa chilena sobre sociedades y concursos.

En lo que sigue nos concentraremos entonces en la revisión de tres formas distintas de abordar el fenómeno de la responsabilidad intra y extragrupal: el sistema alemán, que establece un particular mecanismo de compensaciones y de acciones indirectas de responsabilidad de los acreedores y accionistas minoritarios de la sociedad dominada en insolvencia; el sistema italiano, que incorpora como elemento de análisis de la responsabilidad el "interés del grupo", contemplando esta vez acciones directas en favor de los acreedores y de los accionistas minoritarios; y el sistema argentino, que consagra un régimen especial de extensión de la quiebra. Advirtamos, con todo, que existen otros ordenamientos que, como el español ${ }^{23}$, no regulan de manera específica los grupos empresariales, pero contemplan no obstante algunas normas concursales que se ocupan de la insolvencia de sociedades agrupadas.

23 La Ley concursal española 22/2003 contempla diversas normas de carácter informativo y procesal, que reconocen la particular realidad de las sociedades insolventes que pertenecen a un grupo a través de medidas que facilitan el reconocimiento de la dependencia o vinculación societaria como elemento relevante del concurso en el contexto de sociedades agrupadas. Así por ejemplo, el art. 25.2. permite al acreedor "solicitar la declaración judicial conjunta de concurso de varios de sus deudores, cuando sean cónyuges, exista entre ellos confusión de patrimonios o formen parte del mismo grupo de sociedades". El art. 25 bis, a su turno, establece que "Cualquiera de los concursados o cualquiera de las administraciones concursales podrá solicitar al juez, mediante escrito razonado, la acumulación de los concursos ya declarados siguientes: $1^{\circ}$ De quienes formen parte de un grupo de sociedades". En cuanto al deber de información, el art. 6.2.2. de la LC exige que en su solicitud de declaración de concurso el deudor persona jurídica indique "si forma parte de un grupo de empresas, enumerando las entidades integradas en este, y si tiene admitidos valores a cotización en mercado secundario oficial”. Los artículos 92.4 y 93.2.3. tratan asimismo de la subordinación de créditos en el caso de sociedades integradas a un grupo. Por último, especial interés tienen aquellas disposiciones que permiten imponer a la sociedad dominante alguna responsabilidad por su dirección sobre la filial que ha devenido insolvente, y la especial y reiterada mención que hace la LC a la figura del administrador de hecho (v. gr. arts. 8.7, 48 ter y 172.2.1 LC). 


\subsection{Sistema alemán}

Como se adelantó supra, según su origen el derecho alemán reconoce dos tipos de grupos empresariales: el de naturaleza contractual, derivado de un contrato de dominación (Vertragskonzern) y el de facto (Faktische Konzerne), cuya génesis se sitúa extramuros de ese ámbito contractual. Considerando que el derecho chileno no contempla la figura contractual recién mencionada, solo nos referiremos aquí al sistema de responsabilidad que establece la $A k t G$ respecto de los grupos de hecho.

La legislación alemana contempla en este punto un complejo sistema normativo, que apunta básicamente a preservar el interés de la sociedad dominada por la vía de proscribir de forma genérica las instrucciones perjudiciales de la matriz, y de sancionar en su caso la infracción de tal prohibición mediante la reparación integra de los perjuicios causados a la sociedad y a sus accionistas. Según el art. 311.1 de la $A k t G$, en efecto, "En ausencia de un contrato de dominación, la empresa dominante no puede utilizar su influencia para inducir a una sociedad dependiente, anónima o comanditaria por acciones, a que concluya un negocio jurídico o adopte medidas en perjuicio suyo $u$ omita uno y otras, a no ser que se compensen los perjuicios". Por su parte, el art. 317.1 señala que "Si una empresa dominante induce a una sociedad dependiente, con la cual no ha concluido contrato de dominación alguno, a que lleve a cabo un negocio jurídico perjudicial para ella, o a que adopte u omita una medida en su perjuicio, sin que se compense efectivamente el daño hasta el final del ejercicio, o le conceda a la sociedad dependiente acción sobre una ventaja a efectos de la compensación, tendrá la obligación de indemnizar a la sociedad por los daños que tales hechos le produzcan. También tendrá la obligación de indemnizar a los accionistas del daño sufrido por ellos, siempre que hayan sido perjudicados con independencia del daño que hayan podido sufrir como consecuencia del perjuicio de la sociedad”.

Se trata, por ende, de un mecanismo de responsabilidad indirecta de la matriz por la insolvencia de la filial, en donde los acreedores de esta última carecen de una acción en contra de aquella para hacer efectiva tal responsabilidad. La tutela de sus derechos, por ende, se estructura con base en un sistema de compensaciones que opera ex post y que apunta, básicamente, a restablecer la indemnidad patrimonial de la dominada/deudora en términos fragmentarios o puntuales ${ }^{24}$.

Distinta es la situación tratándose de los administradores de la sociedad filial, pues aparte de la falta de compensación de los daños causados por la matriz debe concurrir, como requisito adicional, el incumplimiento del deber de diligencia o cuidado que para estos casos establece el art. 312 de la $A k t G$, en relación con el art. 318 de la misma ley. Según la primera norma citada, los administradores de la filial -cuando no existe contrato de dominación, reitero- están obligados a confeccionar un informe sobre las relaciones de la misma con las demás agrupadas (informe de dependencia o Abhängigkeitsbericht), indicando en él si aquella ha recibido o no en cada caso o negocio perjudicial una contraprestación adecuada de la matriz, o si al menos se le ha otorgado algún título en que le reconozca tal

${ }^{24}$ La propia ley se encarga de precisar que el deber de compensación opera con respecto a cada negocio jurídico concreto o medida perjudicial en particular, descartando la posibilidad de optar a una compensación global de todas las pérdidas sufridas por la sociedad dominada [cfr. Miguens (2006) pp. 414 y 415 ]. 
JEQUier LeHUEDÉ, Eduardo — "Responsabilidad por insolvencia en los grupos empresariales..."

derecho a futuro ${ }^{25}$. De esta forma, los administradores responderán en este caso no por la falta de compensación en sí misma, sino por la infracción de su deber de cuidado al confeccionar el informe mencionado y al supervisar, por ende, que la compensación dada u ofrecida ha sido completa.

Sin perjuicio de lo anterior, la legislación alemana ofrece también algunos ejemplos sobre responsabilidad del administrador de hecho, aplicables a los casos de insolvencia intragrupal. Así, los artículos 82 y 84 de la Ley de Sociedades de Responsabilidad Limitada ( Gm$b H G)$ castigan con penas privativas de libertad o multas a quienes, como administradores, efectúen indicaciones falsas, omitan indicar a los socios pérdidas que alcancen la mitad del capital social o no soliciten, en el caso de insolvencia o endeudamiento excesivo, la apertura del procedimiento de quiebra o del procedimiento conciliatorio judicial. Por su parte, el art. 117 de la $A k t G$ contempla la denominada "cláusula de responsabilidad del derecho accionarial" (aktienrechtliche Haftungsklausel) ${ }^{26}$, que hace extensiva la responsabilidad por insolvencia a quien, ejercitando dolosamente su influencia sobre la sociedad, incite a un administrador o a un miembro del consejo de vigilancia a actuar en perjuicio de la misma ${ }^{27}$.

\subsection{Sistema italiano: la doctrina de las ventajas compensatorias}

Una primera manifestación de la legislación italiana en este punto se encuentra en la Ley $\mathrm{N}^{\circ}$ 95/1979, sobre administración extraordinaria de grandes empresas en crisis, conocida como también como "Legge Prodi" por el nombre de su promotor. Esta ley contempló una noción de grupo, para efectos concursales, e hizo responsables a los directores de la sociedad matriz por la insolvencia de una sociedad subsidiaria sujeta a una dirección unitaria y en estado de cesación de pagos ${ }^{28}$.

En la actualidad, el sistema italiano muestra dos vertientes normativas distintas respecto de la responsabilidad de la sociedad matriz de cara al ejercicio dañoso de su dirección unitaria. Por una parte, el art. 90 del Decreto Legislativo 270/99, de 8 de julio de 1999, sobre "Nuova disciplina dell'amministrazione straordinaria delle grandi imprese in stato di in-

25 Vid. Krieger (1999) p. 997 y ss.

26 Vid. López (2014) p. 134.

27 El art. 117.1 de la $A k t G$ señala: "1. Quien utilizando su influencia sobre la sociedad incita dolosamente a un miembro de la Dirección o del Consejo de Vigilancia, a un apoderado general o a un apoderado especial, a actuar en perjuicio de la sociedad o sus accionistas, estará obligado frente a la sociedad a indemnizar los daños producidos. También está obligado a indemnizar los daños a los accionistas, si se trata de daños sufridos independientemente de los experimentados por la sociedad". En su numeral 5, la disposición agrega: “5. La acción de indemnización de la sociedad podrá interponerse también por sus acreedores, si no pueden obtener satisfacción de aquella. Frente a los acreedores no se suspende el deber de indemnizar, ni por renuncia ni por transacción de la sociedad, ni porque la acción esté basada en un acuerdo de la Junta general. Si se ha iniciado un procedimiento de insolvencia sobre el patrimonio de la sociedad, el derecho de los acreedores será ejercido durante este tiempo por el administrador del concurso o por el interventor”.

28 La ley Prodi contemplaba la posibilidad de que el Estado italiano garantizara el pago de los pasivos de las grandes empresas concursadas, lo que motivó su derogación en el año 1999 por ser contraria al principio general de no asistencia estatal a las empresas nacionales contemplado -entre otras muchas normas especiales- en los arts. 107 a 109 del Tratado de Funcionamiento de la Unión Europea. 
solvenza, a norma dell'articolo 1 della legge 30 luglio 1998, n. 274", se ocupa de regular dicha responsabilidad en caso de insolvencia al interior del grupo, por la insolvencia de la filial ${ }^{29}$.

Por otra parte, los artículos 2497 y ss. del Código Civil se ocupan de la misma responsabilidad pero en su ámbito externo o extragrupal, esto es, la que recae sobre la matriz y sus administradores ${ }^{30}$ de cara a los derechos de los acreedores y accionistas minoritarios de la sociedad filial en insolvencia.

En este último sentido, desde antes de la reforma del Código Civil, introducida por el Decreto Legislativo 6/2003, la doctrina y la jurisprudencia italianas -o al menos una importante corriente dentro de ellas- fueron modelando una nueva forma de abordar la responsabilidad de los administradores al interior de los grupos empresariales. Así, y como observan QUATRARO y PICONE ${ }^{31}$, el régimen de responsabilidad aplicable en caso de conflicto de intereses constituía la principal limitante para el funcionamiento de los grupos empresariales en Italia, pues en ese esquema los administradores debían abstenerse de realizar cualquier acto que pudiese causar un perjuicio a la sociedad respectiva aunque estuviese integrada a un grupo.

Esta concepción, sin embargo, fue derivando paulatinamente -por iniciativa doctrinal y jurisprudencial como se dijo- en una noción más amplia y ajustada a la realidad de los grupos empresariales, superadora por lo mismo de la dinámica de intereses concurrentes en las sociedades-isla. De esta forma, al análisis de la conducta antijurídica de los administradores de sociedades agrupadas y de la responsabilidad aneja a ella por el daño causado, se incorporó un factor adicional y propio de este particular fenómeno: el interés del grupo. El planteamiento, básicamente, consistía en sostener que la consecución del interés del grupo, en detrimento incluso del interés de la sociedad dominada, debía ser considerado como un elemento interpretativo indispensable de la señalada conducta, pues, como apunta la doctrina especializada ${ }^{32}$, la responsabilidad de la matriz y de los administradores de la dominada depende en definitiva -para esta tesis- "de la ponderación de las ventajas y desventajas que la pertenencia al grupo acarreaba para dicha sociedad”. Según esto, en fin, aun cuando una determinada operación o negocio jurídico resulte perjudicial para la filial, ni su controladora ni los administradores de aquella deben responder por los perjuicios (a) si las razones que llevaron a la matriz a dar la instrucción de realizar la operación dañosa se enmarca en

29 Art. 90. Acción revocatoria.

1. Sin perjuicio de lo establecido en el artículo 49, apartado 1, el comisario extraordinario y el curador de la empresa declarada insolvente pueden presentar la acción revocatoria prevista en el artículo 67 de la ley de quiebra en contra de las empresas del grupo en relación con los actos indicados en los números 1), 2) y 3) del mismo artículo realizados en los cinco años anteriores a la declaración del estado de insolvencia, y en relación a los actos indicados en el número 4) apartado segundo del mismo artículo, realizados en los tres años anteriores. 2. Para efectos de la presentación de la acción, el comisario extraordinario y el curador pueden pedir las informaciones previstas en el artículo 83". Traducción libre del autor.

30 Debe advertirse que la doctrina italiana no es uniforme en cuanto a la posibilidad de aplicar esta figura de responsabilidad a la sociedad matriz como tal, tanto por razones de historia de la ley como de política jurídica de protección de los acreedores de la sociedad matriz, que podrían verse perjudicados con esta medida de extensión de responsabilidad. Por todos, AbBadessa(1982) p. 144.

31 Quatraro y Picone (1998) p. 566.

32 Quatraro y Picone (1998) p. 570. 
una política de grupo elaborada por esta última, que al impartirse resultaba coherente con el interés del mismo; (b) si al adoptarse la instrucción, el perjuicio de la filial resultaba también proporcionado y coherente con sus posibilidades económico-financieras; (c) que al impartirse la directriz se consideró ex ante una contrapartida futura para el sacrificio de la filial, no necesariamente igual ni superior al daño sufrido, sino que adecuado a la relación ponderada entre costes y beneficios razonablemente previsibles ${ }^{33}$.

Tras la reforma del año 2003, ya referida, la tesis de las ventajas compensatorias fue incorporada finalmente al C.C. italiano. En este sentido, los artículos 2497 y ss. nuevos del referido cuerpo legal ${ }^{34}$ consagran una acción directa de los acreedores ${ }^{35}$ y accionistas minoritarios de la dominada en contra de la matriz, la que en todo caso deberá responder -al igual que los administradores de la filial en su caso- no por el solo hecho de ejecutar la instrucción perjudicial sino, al igual que en el sistema alemán ya visto, cuando adicionalmente no ha existido una adecuada motivación de dicha instrucción, en los términos del art. 2497 ter del C.C.

\subsection{La extensión de la quiebra en el sistema argentino}

Más drástica ha sido la solución adoptada en este sentido por la legislación argentina, que en ciertos extremos hace extensiva la quiebra de la dominada al controlador.

La figura de la extensión de la quiebra tiene su origen en la costumbre mercantil que modeló el derecho estatutario medieval italiano en general, en un contexto histórico en donde la sociedad se caracterizaba por carecer de personalidad jurídica. Por lo mismo, no era la quiebra de la sociedad la que se hacía extensiva, sino que aquella se originaba en la corresponsabilidad ilimitada que asumían los socios en el ejercicio empresarial. Eran, pues, "los auténticos cesantes o fugitivos, que habrían manifestado su situación patrimonial a través de la insolvencia de la negociato" 36 .

A fines del siglo XVIII y principios del XIX, sin embargo, las corrientes codificadoras y la personificación de la sociedad, como sujeto jurídico distinto de los socios, generaron las primeras críticas - que se mantienen hasta hoy y que compartimos- en cuanto a la viabilidad dogmática y la conveniencia de esta figura, pues por esta vía se somete a concurso a los socios no por su propia insolvencia, como ocurría en sus orígenes, sino por la de la sociedad. Pese a ello, tanto el Código de Comercio francés de 1807 (concretamente tras

\footnotetext{
33 Fuentes Naharro (2007) p. 204.

34 El art. 2497 señala (párrafo I): "La sociedad o ente que, ejercitando una actividad de dirección y coordinación de otras sociedades, perjudique el interés empresarial propio o de otros violando los principios de correcta gestión societaria y empresarial de la sociedad, será directamente responsable frente a los socios de esta por el perjuicio infligido a la rentabilidad y al valor de sus participaciones sociales, y frente a sus acreedores por la lesión ocasionada a la integridad del patrimonio social. No será exigible tal responsabilidad cuando el daño resulte inexistente a la luz del resultado global de la actividad de dirección y coordinación o cuando haya sido integralmente eliminado a continuación de la operación en cuestión”. Traducción libre del autor.

35 Si la sociedad dominada es sometida a concurso por insolvencia, el párrafo IV del art. 2497 del C.C. italiano concede también acción directa a los acreedores, en contra de la sociedad matriz y de sus administradores: "[IV] En caso de quiebra, liquidación y administración extraordinaria de la sociedad sujeta a la dirección y coordinación de otras sociedades, la acción de los acreedores en virtud del presente [artículo] será ejercida por el curador o por el comisario liquidador o por el comisario especial”. Traducción libre del autor.

36 Gonzalo López (2001) p. 45.
} 
la reforma de 1838, arts. 531 a 604) como el español de 1829 (arts. 297, 1022 y 1047) la mantuvieron, tal vez por la amplia aceptación de que gozaba en el comercio y como forma de privilegiar a los acreedores sociales respecto de los personales de los socios. Lo propio ocurrió con el Código belga de 1851 (arts. 440.II, 473, 530 y 586).

En la legislación concursal chilena, y por influencia de las codificaciones recién mencionadas, la extensión de la quiebra fue reconocida y se mantuvo por más de un siglo y medio, partiendo por el derogado art. 1329 del Código de Comercio de 1865, hasta desaparecer por completo con la reciente Ley $\mathrm{N}^{\circ}$ 20.720, del año 2014. Esta última, como ya se explicó, derogó la LQ y con ella su art. 51, sobre quiebra consecuencial o por extensión del socio de una sociedad colectiva o comandita comercial, lo que constituye a nuestro juicio un acierto si se considera el origen histórico de la figura y la incompatibilidad dogmática ya descrita.

Distinto es el caso de la legislación argentina, que mantiene hasta hoy la extensión de la quiebra aunque con una inspiración también muy diferente a la recién mencionada (Capítulo III de la Ley No 24.522, de 20 de enero de 1995, arts. 160 y ss.). Dice en este sentido el artículo 161 de la Ley concursal: "La quiebra se extiende: 1) A toda persona que, bajo la apariencia de la actuación de la quebrada, ha efectuado los actos en su interés personal y dispuesto de los bienes como si fueran propios, en fraude a sus acreedores. 2) A toda persona controlante de la sociedad fallida, cuando ha desviado indebidamente el interés social de la controlada, sometiéndola a una dirección unificada en interés de la controlante o del grupo económico del que forma parte. A los fines de esta sección, se entiende por persona controlante:

a) Aquella que en forma directa o por intermedio de una sociedad a su vez controlada, posee participación, por cualquier título, que otorgue los votos necesarios para formar la voluntad social;

b) Cada una de las personas que, actuando conjuntamente, poseen participación en la proporción indicada en el párrafo a) precedente y sean responsables de la conducta descrita en el primer párrafo de este inciso. 3) A toda persona respecto de la cual existe confusión patrimonial inescindible, que impida la clara delimitación de sus activos y pasivos o de la mayor parte de ellos".

Por su parte, el art. 172 aclara que "Cuando dos o más personas formen grupos económicos, aun manifestado por relaciones de control pero sin las características prevista en el Artículo 161, la quiebra de una de ellas no se extienden a las restantes".

De las normas referidas se desprende que la ley acota el ámbito material y subjetivo de la extensión de la quiebra a los supuestos de abuso de los bienes de la sociedad concursada, a los casos de abuso de la dirección unitaria y a aquellas situaciones de confusión patrimonial inescindible. Según la doctrina ${ }^{37}$, además, cuatro son los requisitos que deben concurrir para hacer extensiva la quiebra a la sociedad dominante: a) que la controladora detente el control sobre la filial fallida; b) que la fallida sea parte del grupo empresarial de la matriz; c) que mediante el abuso de la dirección unitaria, la matriz hubiese afectado el

37 Por todos Foiguel Borci (2013). 
interés de la sociedad controlada en falencia; y d) Que esta conducta de la matriz haya causado, mantenido, agravado o prolongado el estado de cesación de pagos. La jurisprudencia, por su parte, ha optado por verificar la inexistencia de una suficiente compensación de los perjuicios causados a la controlada por parte de la dominante, como paso previo a declarar la extensión de la quiebra ${ }^{38}$.

Con todo, nos parece que la figura de la extensión de la quiebra, aun en el esquema planteado por el legislador argentino, resulta contraproducente de cara al derecho de prenda general de los acreedores de la sociedad concursada por extensión, que se verá confundido con el de los acreedores de la filial. Asimismo, una solución como esta resulta contradictoria con el fin de última ratio del proceso concursal, que no es otro que dar solución a un estado permanente y profundo de insolvencia que, en el caso de aquellas personas a quienes se extiende la quiebra, no existe necesariamente.

\section{RESPONSABILIDAD POR INSOLVENCIA EN EL GRUPO EMPRESARIAL Y TEORÍA DEL ADMINISTRADOR DE HECHO}

La legislación chilena, junto con reconocer y regular la figura de las sociedades relacionadas en cuanto vehículo de control indirecto y nutriente -a su turno- de la formación de grupos de sociedades, ha concentrado sus esfuerzos en el perfeccionamiento de los mecanismos de ejercicio del control y en el manejo de la información que producen los grupos empresariales de cara al funcionamiento del mercado de valores. Sin embargo, situaciones de insolvencia como las que han afectado y que afectan actualmente a importantes grupos empresariales chilenos no encuentran una respuesta clara en la legislación concursal chilena, entrampada todavía en la endémica conceptualización de la insolvencia como un fenómeno propio de sociedades-isla.

El panorama recién descrito distorsiona sin duda los objetivos y el normal funcionamiento de las tutelas colectivas que contempla la ley concursal, pues parece evidente que los acreedores de la sociedad controlada se verán forzados en cierto modo a aceptar el planteamiento ad libitum del controlador del grupo - pese a que ha provocado o agravado precisamente dicha insolvencia- si la única alternativa que queda (pues la ley no conoce otra) es la liquidación de los activos del (los) miembro(s) insolvente(s) individualmente considerado(s). Todavía más, y en lo que concierne a la responsabilidad por la insolvencia y la oportuna declaración del concurso de la sociedad dominada, la propia dinámica de la dirección unitaria del grupo impide muchas veces que los administradores de la misma tengan una visión clara de dicho estado y de la real situación financiera de la empresa (que solo conocen la matriz y sus administradores), lo que amén de retrasar el inicio del concurso -y de mermar por ende su eficacia- impide hacer efectiva la responsabilidad de aquellos

\footnotetext{
38 Así lo señaló la Cámara Nacional de Comercio: "El desvío indebido del interés social acaece cuando la actividad económica de la controlada es desfavorecida para satisfacer el interés del grupo sin que exista reciprocidad. Tal desvío importa la transferencia de beneficios a favor de terceros sin contraprestación adecuada o insuficiente" (sentencia de 29 de diciembre de 1999, Sala A, autos "Castelar S.A. s/Quiebra s/inc. de Extensión de Quiebra). En similar sentido el mismo tribunal, Sala B, sentencia de 18 de diciembre de 1998, autos "Fibrasur s/Quiebra s/Extensión de Quiebra”.
} 
en cuanto administradores de derecho de la sociedad insolvente. Como señala Sánchez Calero ${ }^{39}$, en fin, “(..) se atisba desde un primer momento una relevante divergencia entre la identidad de aquellos a quienes la LC atribuye la competencia de solicitar la iniciación del concurso y la responsabilidad por no hacerlo oportunamente (v. art. 3.1, párrafo segundo LC), y la de aquellos otros quienes, sin ser titulares formales de esa competencia, son quienes la detentan desde un punto de vista material. Son estos quienes, a la postre, deciden la solvencia o insolvencia de la sociedad dependiente".

Lo anterior, en síntesis, ha llevado a la mayoría de los ordenamientos comparados $-y$ a prácticamente todos los del ámbito europeo continental- a ampliar el concepto de administrador de la sociedad dominada para hacerlo extensivo a la matriz y a sus administradores de derecho, quienes asumen en este sentido el carácter de administradores de hecho y, con ello, la misma responsabilidad que el ordenamiento jurídico les impone a los primeros por la insolvencia de la sociedad dominada.

No nos detendremos aquí a analizar en detalle la figura del administrador de hecho y sus variantes, pues a ello y a su posible implementación en el derecho chileno nos hemos referido ya en un trabajo anterior de carácter general, al que nos remitimos ${ }^{40}$. Más que eso, y habiendo revisado ya la situación actual del derecho concursal chileno y algunas de las principales herramientas legislativas implementadas en el derecho comparado, nos proponemos demostrar en esta investigación la conveniencia de considerar al administrador de hecho como vehículo idóneo para hacer efectiva la responsabilidad intra y extragrupal de la controladora y/o de sus administradores de derecho, por la insolvencia de la sociedad sujeta al régimen de dirección unitaria.

\section{BREVE REFERENCIA A LA RESPONSABILIDAD DEL ADMINISTRADOR DE HECHO DEL GRUPO EN EL DERECHO FRANCÉS Y ESPAÑOL}

En el apartado anterior mencionamos algunas legislaciones que se han ocupado de regular expresamente a los grupos empresariales, como ocurre en Alemania, las que contemplan diversas acciones - directas e indirectas- para hacer efectiva la responsabilidad del controlador y que, de manera explícita o implícita, recogen para ello los elementos característicos de la teoría del administrador de hecho. Por su parte, en aquellos países que por simple omisión o por opción propia no han regulado los grupos empresariales, la figura del administrador de hecho ha venido a llenar los espacios en materia de responsabilidad del ente dominante por la insolvencia de la dominada, primero por iniciativa doctrinal y jurisprudencial y luego mediante el expreso reconocimiento del legislador como ha ocurrido en el derecho español y francés.

Tras su reforma en el año 2011 (Ley $N^{\circ}$ 38/2011, de 10 de octubre), la Ley concursal española 22/2003 -LCE-, siguiendo en esto a la derogada LSA de $1989^{41}$, se ocupó

39 Sánchez-Calero (2005) pp. 35 y 36.

40 JeQUier (2014) p. 138 y ss.

${ }^{41}$ La figura del administrador de hecho fue expresamente incorporada en el art. 133.2 de la LSA, mediante Ley núm. 26/2003, de 17 de julio. Antes, sin embargo, la jurisprudencia había reconocido ya su existencia, como se observa en las sentencias del TS de fecha 26 de mayo de 1998 (Id. Aranzadi Westlaw: RJ 199814004) y de 24 de 
JEQUIER LEHUEDÉ, Eduardo — "Responsabilidad por insolvencia en los grupos empresariales..."

especialmente del fenómeno de los grupos empresariales, partiendo por definirlos para efectos de la $\mathrm{LC}^{42}$ aunque sin considerarlos como una situación especial de insolvencia. Como alternativa a esa opción, lo que hizo el legislador fue incluir a los grupos empresariales como un supuesto más de concursos conexos, regulados en el Capítulo III, Título I de la LC (en particular los arts. 25.2 y 25 bis 1.1), lo que ha llevado a una parte de la doctrina a asignarle a esta reforma un carácter esencialmente procesal ${ }^{43}$. Con todo, y en lo que aquí nos interesa destacar, la ley de reforma reguló expresamente la figura del administrador de hecho $^{44} \mathrm{y}$, con ella, la posibilidad de hacerlo responsable por la insolvencia de la persona concursada, lo que constituye un notorio avance:

a) En primer término, el art. 8.7 de la LC, refiriéndose al Juez del concurso, contempla expresamente al administrador de hecho como sujeto pasivo de la acción de responsabilidad.

b) Relacionado con lo anterior, los artículos 164 y 165 de la LCE permiten calificar la quiebra como culpable y sancionar -entre otros- a los administradores de hecho, en los términos del art. 172 de la misma Ley, sin perjuicio de la posibilidad de condenarlos además a cubrir total o parcialmente el déficit que arroje el concurso, según señala el art. 172 bis $^{45}$.

c) El artículo 166 de la misma ley contempla también la figura de la complicidad de los administradores de hecho en la calificación de la quiebra como culpable.

d) El art. 48 ter de la LCE, aplicable a todos los supuestos anteriores, señala que "Desde la declaración de concurso de persona jurídica, el juez del concurso, de oficio o a solicitud razonada de la administración concursal, podrá acordar, como medida

septiembre de 2001 (Id. Aranzadi Westlaw RJ 2001\7489), por mencionar algunas. Actualmente, en lo sustancial la misma norma se contiene en el art. 236 de la Ley de Sociedades de Capital, del año 2010.

42 La ley de reforma incorporó la disposición adicional Sexta de la LC, que señala: "Grupo de sociedades. A los efectos de esta ley, se entenderá por grupo de sociedades lo dispuesto en el artículo 42.1 del Código de Comercio", que se refiere sin embargo al ámbito contable y concretamente a "las cuentas anuales y el informe de gestión consolidados" de las empresas de grupo.

43 Por todos Sánchez-Calero y Naharro (2012) p. 8. Los mismos autores entienden por concursos conexos para estos efectos "la simultánea o próxima insolvencia de dos o más sociedades que formen parte de un grupo de sociedades" [SÁnChez-CALero y NAHARro (2012) p. 9]. El carácter procesal de la reforma, a su vez, se evidencia en que la LC aborda la particular realidad de la insolvencia intragrupal mediante herramientas que tienen ese concreto carácter y que se manifiestan además en distintos momentos del procedimiento: en sus inicios, mediante la figura de la declaración conjunta de los concursos, y durante su desarrollo a través de la acumulación de concursos ya declarados por cuerdas separadas.

44 La LC española no define el concepto de administrador de hecho. Sin embargo, en el apartado VI de la Memoria que acompañó al último Anteproyecto de Ley, del año 2002, se señaló que el concepto de administrador de hecho era el utilizado por la doctrina y jurisprudencia penal, esto es, uno de carácter amplio y funcional, que considera como tal a todo aquel que ejerce real y efectivamente la gestión de la sociedad. Al respecto puede consultarse a Rojo Fernández-Río (2003) pp. 49 y ss.

45 La persona afectada por la calificación del concurso es el deudor. Si se trata de una persona jurídica, para que la calificación prospere es necesario que la insolvencia -o su agravación- provenga de una actuación u omisión culpable de los administradores de derecho o de hecho, o de los liquidadores de la sociedad, lo que justifica precisamente que para la legislación española estos últimos -administradores y liquidadores- y los apoderados generales deban suplir en esos casos el déficit concursal. 
cautelar, el embargo de bienes y derechos de sus administradores o liquidadores, de hecho y de derecho (...)".

Similar es el panorama en el derecho francés. A partir de una serie de sentencias de la Cour de Cassation, se fueron construyendo las bases de una legislación actual que si bien no regula el fenómeno del grupo empresarial, contempla no obstante diversas disposiciones particulares sobre la responsabilidad del administrador de hecho ${ }^{46}$. Emblemática es en este sentido la sentencia penal dictada en el caso Rozenblum ${ }^{47}$, que dio origen precisamente a la doctrina del mismo nombre y que reconoció la existencia y responsabilidad del denominado dirigeant de fait ${ }^{48}$, esto es, de aquella "persona física o moral que toma efectivamente las decisiones sin ejercitar una función oficial en la sociedad" ${ }^{49}$. Según esta doctrina, en resumen, el ejercicio legítimo de la dirección unitaria del grupo presupone tres requisitos concretos: a) que las directrices o instrucciones del controlador se encuadren dentro del interés común del grupo y de una política coherente de dirección; b) que exista en todo caso una contrapartida económica suficiente para la sociedad dominada que soporta el perjuicio; y c) que dicha carga no supere las reales posibilidades financieras de la misma ${ }^{50}$.

En el ámbito latinoamericano, por último, especial mención merecen las leyes concursales de Uruguay y Colombia:

a) El art. 248 de la Ley concursal uruguaya, No 18.387 sobre "Declaración judicial del concurso y reorganización empresarial" -LCU-, tipifica como delito la conducta del deudor que "en oportunidad de la solicitud del concurso o en cualquier etapa posterior, exagere u oculte su activo o su pasivo, reconozca o aparente privilegios inexistentes o constituidos ilícitamente, sustraiga o esconda los libros sociales, acuerde u otorgue a sus acreedores con cargo a la masa activa ventajas particulares en razón de

\footnotetext{
46 Sobre la responsabilidad en el ámbito grupal en Francia puede consultarse a PARIENTE (1993).

47 Cass. Crim. de 4 de febrero de 1985. Puede consultarse en: Juris-ClasseurPériodique (La Semaine Juridique), II, 1985, pp. 681 y ss. (con comentario de W. Jeandidier).

48 Dice en este sentido la sentencia: "Pour échapper aux prévisions des articles 425 et 437 de la loi du 24 juillet, le concours financier apporté par les dirigeants de fait ou de droit d'une société à une autre entreprise d'un même groupe dans laquelle ils sont intéressés directement ou indirectement, doit être dicté par l'intérêt économique social ou financier commun, apprécié au regard d'une politique élaborée por l'ensemble de ce groupe, il ne doit ni être démuni de contreparties ou rompre l'equilibre entre les engagements respectifs des diverses sociétés concernées, ni exceder les possibilités financières de celles qui en supportent la charge (...)".

49 Ostek (1982) p. 339. Traducción libre del autor.

50 Debe advertirse, sin embargo, que la doctrina Rozenblum ha generado importantes dudas doctrinales en cuanto a su viabilidad como base para la regulación de los grupos. Como apunta Girgado (2002, op. cit., pp. 55 y 56), un sector doctrinal acusa la incompatibilidad de esta tesis con las Directivas comunitarias sobre sociedades, pues mientras la primera recoge el criterio de la enterprise law, las restantes -las Directivas- discurrirían sobre la base de la entity law. Del mismo modo, se le ha criticado su inspiración debilitadora del órgano de dirección de la sociedad filial, las dificultades para interpretar sus elementos (v.gr. los tiempos que deben contemplarse para ello, o la persona, autoridad u órgano llamado a definirlos) y, en fin, los problemas probatorios que implica definir lo que debe ser una adecuada o suficiente compensación. No obstante, esta doctrina ha influido sustancialmente en el desarrollo de la figura del administrador de hecho en Francia y en todo el ámbito comunitario, como dan cuenta por ejemplo las propuestas del Forum Europeaum en materia de grupos, inspiradas en buena medida en la doctrina Rozenblum [vid. WindBichler (2000), en especial p. 367 y ss.]
} 
JEQUIER LeHUEDÉ, Eduardo " "Responsabilidad por insolvencia en los grupos empresariales..."

su voto", sancionándolo con una pena de "un año de prisión a cinco años de penitenciaría". El inciso $2^{\circ}$, en lo que aquí interesa, establece que "En el caso de las personas jurídicas, incurrirán en este delito los socios, directores, administradores, de hecho o de derecho, que hayan aprobado la realización o hayan realizado los actos constitutivos del delito". En cuanto a la responsabilidad civil del administrador de hecho, la LCU contempla también diversas disposiciones, similares por cierto a las ya mencionadas de la LCE, en las que se refiere al administrador de hecho aunque sin llegar tampoco a definirlo. Así, por ejemplo, el art. 122.2, letra b) de la LCU contiene una norma muy similar al art. 93.2.2 de la LCE, con la sola diferencia de que aquella no hace extensivo el concepto de personas relacionadas a los cesionarios o adjudicatarios de créditos pertenecientes a los administradores de hecho. El art. 192 LCU $^{51}$, por su lado, es sustancialmente idéntico al art. 164.1 de la LCE. El art 201 de la LCU, por último, se asemeja mucho también al art. 172 bis de la LCE, al disponer que si se declara como culpable el concurso de una persona jurídica, "la sentencia de calificación podrá contener, además, la condena a los administradores y liquidadores, de derecho o de hecho, e integrantes del órgano de control interno, o a algunos de ellos, a la cobertura de la totalidad o parte del déficit patrimonial en beneficio de la masa pasiva", tal como se hizo por lo demás en una reciente sentencia de calificación ${ }^{52}$.

b) Tratándose de la ley colombiana de Insolvencia Empresarial ( $\mathrm{N}^{\circ} 1.116$, de 20 de junio de 2012), el artículo 61 inc. $1^{\circ}$ de la misma considera implícitamente a la sociedad matriz como administradora de hecho de la filial insolvente, haciéndola subsidiariamente responsable por el déficit concursal. Dice concretamente la norma referida: "De los controlantes. Cuando la situación de insolvencia o de liquidación judicial, haya sido producida por causa o con ocasión de las actuaciones que haya realizado la sociedad matriz o controlante en virtud de la subordinación y en interés de esta o de cualquiera de sus subordinadas y en contra del beneficio de la sociedad en reorganización o proceso de liquidación judicial, la matriz o controlante res-

51 "Art. 192 (Clases de concursos). El concurso de acreedores se calificará como culpable o como fortuito./ El concurso se calificará como culpable cuando en la producción o en la agravación de la insolvencia hubiera existido dolo o culpa grave del deudor o, en caso de personas jurídicas, de sus administradores o de sus liquidadores, de derecho o de hecho./En los demás casos se calificará como fortuito".

52 Vid. sentencia 818 del Juzgado Letras en lo Concursal de 2do Turno, de 6 de junio de 2013, autos caratulados “GELITUR S.A. CONCURSO - INCIDENTE DE CALIFICACIÓN», IUE 41-50/2011”, que en su parte resolutiva señala:

“(...) Declárase el concurso de Gelitur SA como culpable en virtud de que durante los dos años anteriores a la fecha de declaración del concurso de acreedores los fondos o los bienes propios del deudor hubieran sido manifiestamente insuficientes o inadecuados para el ejercicio de la actividad o actividades a las que se hubiera dedicado y por haberse incumplido el deber de solicitar la declaración judicial de concurso dentro de los treinta días siguientes a que hubiera conocido o debido conocer su estado de insolvencia.

Inhabilítase a la deudora, a su director Gildo Tomadúz y al administrador de hecho Carlos Álvarez para administrar los bienes propios o ajenos por un período de cinco años, así como para representar a cualquier persona durante el mismo período, oficiándose para su inscripción en el registro nacional de actos personales, sin costo, por no existir recursos suficientes.

Condénase a los administradores de derecho o de hecho, e integrantes del órgano de control interno, Gildo Tomadúz y Carlos Álvarez, a la cobertura de la totalidad del déficit patrimonial en beneficio de la masa pasiva (artículo 201 de la ley no 18.387)”. 
ponderá en forma subsidiaria por las obligaciones de aquella. Se presumirá que la sociedad está en esa situación concursal, por las actuaciones derivadas del control, a menos que la matriz o controlante o sus vinculadas, según el caso, demuestren que esta fue ocasionada por una causa diferente".

2. LA RESPONSABILIDAD DEL ADMINISTRADOR DE HECHO COMO INCENTIVO A LA DEClaración TEMPRANA DEL CONCURSO. UNA LABOR PENDIENTE EN LA LEGISLACIÓN CONCURSAL CHILENA

Tal vez si el primer y principal obstáculo que debe enfrentar todo proceso concursal consiste en prevenir la ineficacia del sistema en su conjunto, a consecuencia de una declaración tardía del concurso ${ }^{53}$. Por ello, los ordenamientos comparados han implementado distintos mecanismos para evitar que el deudor agrave su situación de insolvencia, incentivándolo por distintas vías a solicitar dicha declaración en forma temprana y con miras a minimizar los efectos de dicho estado patrimonial. Como apunta López ${ }^{54}$, en fin, "se tiene la ilusión de que el ingreso del deudor a un proceso concursal, maximizaría las posibilidades de que continúe con su actividad empresarial, logrando acuerdos razonables y convenientes con sus acreedores"; o en último término, se podrá definir más rápidamente si el estado de insolvencia amerita o no una medida de liquidación directa ${ }^{55}$.

Especial énfasis puso el legislador español en este punto, al permitir que el estado de insolvencia se revele a través de cualquier hecho externo, contemplado o no en la LCE; o al autorizar el concurso aun cuando la insolvencia, pese a ser inminente, aun no se ha producido. Asimismo, y siguiendo con los sistemas concursales puestos como ejemplo, los arts. 5 de la LCE y 10 de la LCU exigen que el deudor solicite su propio concurso dentro de los dos meses o de los cinco días siguientes a aquel en que haya conocido o debido conocer su estado de insolvencia, respectivamente, reforzando por último dicho mecanismo por la vía de calificar como culpable el concurso en caso de incumplimiento de dicho deber (arts. 165.1 de la LCE y art. 194.1 de la LCU) y de imponerle a los administradores de hecho -entre otros- la obligación de satisfacer el déficit concursal.

En la legislación chilena, el criterio recién indicado se encuentra parcialmente reflejado en el art. 41 de la LQ -aplicable como se dijo hasta la entrada en vigencia de la Ley $\mathrm{N}^{\circ}$ 20.720-, al imponerle al deudor calificado la obligación de solicitar su propia quiebra "antes de que transcurran quince días contados desde la fecha en que haya cesado en el pago de una obligación mercantil”. En caso de infracción a dicha obligación, la misma ley priva al deudor de su derecho a solicitar alimentos a la masa (art. 60), tipificando además su conducta omisiva como delito de quiebra culpable (art. $219 \mathrm{~N}^{\circ} 4$ de la LQ). En consecuencia, la LQ -y ahora también la LRL- omite toda referencia a una responsabilidad civil autónoma derivada de la calificación del concurso, que obligue a responder eventualmente por el déficit como ocurre en las leyes española y uruguaya, lo que se ha traducido en la completa ineficacia del sistema en general y de la obligación del art. 41 en particular. Este último, en

\footnotetext{
53 Vid. Cerdá Albero (2005) p. 955.

54 LÓPEZ (2014) p. 266.

55 Vid. Gebhardt (2009) pp. 305 y 306.
} 
JEQUiER LEHUEDÉ, Eduardo — "Responsabilidad por insolvencia en los grupos empresariales...”

fin, no pasa de ser una declaración lírica sin mayores consecuencias patrimoniales para el deudor; y en lo que aquí postulamos, para el administrador de hecho.

La LRL, por su parte, cambia el panorama aunque no mejora sustancialmente la situación descrita. Así, en el Capítulo IV, Título $1^{\circ}$, Párrafo $1^{\circ}$, art. 115 y ss., la Ley $\mathrm{N}^{\circ}$ 20.720 , en vez de complementar la obligación de solicitar la declaración del propio concurso con una acción autónoma de responsabilidad civil por déficit, opta por un procedimiento de solicitud voluntaria de liquidación por parte del deudor insolvente, eliminándose por ende toda forma compulsiva en tal sentido, y sus respectivas sanciones. La liquidación forzosa directa, por su parte, procede solo por declaración judicial y a solicitud de cualquier acreedor (art. 117 LRL), previa tramitación -dependiendo de la actitud del deudor demandado- del denominado "juicio de oposición”, que podrá fundarse en cualquiera de las excepciones que contempla para el procedimiento ejecutivo el artículo 464 del Código de Procedimiento Civil. La declaración indirecta, por último, al igual que en la LQ tratándose de los convenios judiciales ${ }^{56}$, deberá hacerse por el tribunal competente (a) en caso de retiro sin apoyo de la propuesta de reorganización (art. 77 LRL); (b) por la inasistencia del deudor proponente a la junta de acreedores que debe pronunciarse sobre la propuesta (art. 81 LRL); (c) por la no presentación de una nueva propuesta cuando se ha acogido una impugnación de la propuesta acordada (art. 88 LRL); (d) por el rechazo de la propuesta (art. 96 LRL); y por la declaración de nulidad o incumplimiento del acuerdo, mediante sentencia firme y ejecutoriada (art. 100 LRL).

En síntesis, la LRL elimina las anteriores fórmulas legales orientadas a provocar la declaración temprana del concurso, reemplazándolas por un sistema voluntario de reorganización patrimonial de la empresa deudora que se estimula mediante un régimen de protección financiera concursal (arts. $57 \mathrm{~N}^{\circ} 1,58,88$ y 96 de la LRL) y con otros arbitrios de apoyo a la reorganización ( $v$. gr. la continuidad del suministro del art. 72 o la continuidad de los contratos ex art. $57 \mathrm{~N}^{\circ} 1$, letra “c"). Por ello, el establecimiento de un estatuto eficaz de responsabilidad civil del administrador de hecho en caso de insolvencia se hace especialmente necesario y constituye a nuestro juicio una notoria omisión del legislador, particularmente si se trata de un grupo empresarial. En palabras de Beltrán, en fin, un adecuado sistema de responsabilidad por la generación o la agravación de la insolvencia puede incentivar a que los administradores de sociedades en dificultades económicas, insten el concurso cuando todavía exista la expectativa de una satisfacción razonable de los acreedores ${ }^{57}$.

\section{RESPONSABILIDAD INTRAGRUPAL DE LA SOCIEDAD DOMINANTE POR LA INSOLVENCIA \\ DE LA SOCIEDAD DOMINADA DEL GRUPO. REFERENCIA A LOS DEBERES FIDUCIARIOS. \\ Como hemos dicho en otra oportunidad ${ }^{58}$, a la sociedad matriz o socia controladora del grupo, considerada como administrador de hecho de las filiales integradas al mismo, le}

\footnotetext{
${ }^{56}$ La Ley $\mathrm{N}^{\circ} 20.720$ elimina sin embargo la posibilidad contemplada en el art. 172 de la LQ, que permite a cualquier acreedor que se encuentre en alguno de los casos previstos en los números 1 y 2 del art. 43, solicitar al tribunal competente que obligue al deudor a hacer proposiciones de convenio judicial preventivo.

57 Beltrán Sánchez (2008) p. 348.

58 JeQuier (2014) p. 145.
} 
son exigibles las mismas obligaciones que la ley le impone a los administradores de derecho y, particularmente, los deberes generales de cuidado y lealtad. En toda relación de gestión, en efecto, donde el administrador cuenta con facultades suficientes para afectar la posición jurídica del principal, cobra especial relevancia el principio general del derecho según el cual los contratos deben ejecutarse de buena fe. Lo anterior, pues, impone a aquel en quien el tercero ha depositado su confianza una pluralidad de deberes, que en el caso de los administradores de la sociedad anónima se explican y justifican por la presencia latente del problema de agencia. En otras palabras, y como señala Ribstein ${ }^{59}$, los deberes fiduciarios reducen los costes de agencia y se imponen al gestor, precisamente, cuando su contraparte le ha atribuido la facultad de gestión de su propiedad sin fijarle límites y directrices de conducta concretas. Su denominación como "fiduciarios", por lo mismo, evoca un deber de lealtad y cuidado que, como apunta el juez Cardozo en la sentencia Meinhard v. Salmon ${ }^{60}$, no es solo pura honestidad ni consiste en sujetarse únicamente a la moral del mercado; más que eso, el estándar de cuidado se equipara aquí -metafóricamente hablando- a aquel que debe observar una persona para no afectar el más sensible de los honores.

De esta forma, y por aplicación de los señalados deberes de administración, la sociedad dominante del grupo no podrá privilegiar su propio interés mediante instrucciones que pongan en peligro la solvencia de la filial, ni podría transferir sus beneficios a otras sociedades del grupo sin que exista una razón plausible de negocios para ello, materializada en todo caso -tratándose de sociedades anónimas abiertas- en los términos de los arts. 147 y ss. de la LSA ${ }^{61}$. Por otro lado, la misma LSA contempla el deber general que tiene el directorio en cuanto a informar a los accionistas sobre la marcha de los negocios y la situación legal, económica y financiero-contable de la sociedad y, en el caso de las sociedades abiertas, también a los entes públicos de fiscalización, a las bolsas de valores y al público en general, según el caso (art. 46 de la LSA) ${ }^{62}$. Tal obligación, propia del deber de cuidado o diligencia, resulta también exigible a la dominante como administradora de hecho de la dominada insolvente; máxime si, como se dijo supra, muchas veces los administradores de derecho de esta última no tienen un conocimiento cabal de la real situación financiera de la misma.

La infracción de cualquiera de estos deberes, en síntesis, deriva en la responsabilidad de la sociedad matriz -administrador de hecho- por los perjuicios causados a la filial y a sus accionistas, la que podrá hacerse efectiva en conformidad a las reglas generales sobre

\footnotetext{
59 Ribstein (2011) p. 919.

60 "Joint adventurers, like copartners, owe to one another, while the enterprise continues, the duty of the finest loyalty. Many forms of conduct permissible in a workaday world for those acting at arm's length, are forbidden to those bound by fiduciary ties. A trustee is held to something stricter than the morals of the market place. Not honesty alone, but the punctilio [i.e., a careful observance] of an honor the most sensitive, is then the standard of behavior". New York Court of Appeals, 1928. Citado por Ribstein (2011) p. 903.

61 Girgado (2002) p. 144.

62 Especial mención merece también en este punto la normativa reglamentaria más reciente de la SVS, sobre el deber de cuidado y particularmente sobre el deber de información. Mediante Norma de Carácter General $\mathrm{N}^{\circ} 341$, de 29 de noviembre de 2012, el señalado ente contralor fijó diversas normas para la difusión de información al mercado respecto de los estándares de gobierno corporativo adoptados por las sociedades anónimas abiertas, incluyendo para ello un Anexo de prácticas mínimas esperables en tal sentido. Disponible en:www.svs. cl/sitio/legislacion_normativa/normativa_tramite_ver_archivo.php?id=2012070448\&seq=1
} 
incumplimiento de deberes fiduciarios y con sujeción -en su caso- a las acciones conferidas por los arts. 133 y 133 bis de la LSA; y todo sin perjuicio -a su turno- de la responsabilidad que le cabe a los administradores de derecho de aquella, cuando resulte condenada precisamente a responder por la insolvencia de la filial. Todavía más, y como dijimos también en otro lugar, a través de la figura del administrador de hecho la sola constatación de la existencia del grupo permite presumir iuris tantum, en ciertas ocasiones y con determinados límites ${ }^{63}$, la responsabilidad del controlador y de sus administradores, de quienes es dable esperar un estándar objetivo de diligencia mínima al momento de diseñar e impartir sus directrices a las filiales del grupo ${ }^{64}$.

\section{Responsabilidad EXTRAGRUPAL DE LA SOCIEDAD DOMINANTE POR LA INSOLVENCIA} DE LA SOCIEDAD DOMINADA DEL GRUPO. RECAPITULACIÓN

Hemos dicho supra que la nueva legislación concursal chilena no contempla -ni lo ha hecho antes- una acción directa de responsabilidad civil que puedan ejercer los acreedores de la sociedad filial concursada en contra de la sociedad dominante del grupo, en caso de déficit concursal. Planteamos aquí, por lo mismo, la conveniencia de extender el reconocimiento que se hace de la figura del administrador de hecho en el art. 463 quáter de la LRL, al ámbito de la responsabilidad civil, haciéndolo directamente responsable por ese déficit siempre que incurra en alguna de las conductas indicadas en los arts. 463, 463 bis y 463 ter del Código Penal, introducidos por la misma ley $N^{\circ} 20.720$. Tales conductas, por lo demás, son sustancialmente idénticas a aquellas que considera el art. 164 de la ley concursal española para calificar el concurso como culpable, de manera que no existe razón para confinar la responsabilidad antes referida al puro ámbito penal.

Se trata, en resumidas cuentas, de establecer un régimen de responsabilidad civil "por" la administración de la sociedad concursada, en una concepción funcional amplia que incluye al administrador de hecho, y no "de" los administradores de la misma, que evoca simplemente un sistema propio de las sociedades-isla, al que ya nos hemos referido.

\section{CONCLUSIONES}

En la introducción del presente estudio formulamos una serie de interrogantes que nos propusimos abordar. Sus respuestas concretas se ofrecen a continuación a modo de conclusión:

\footnotetext{
63 JEQUIER (2014) p. 143.

${ }^{64}$ En el sistema inglés, esta dificultad probatoria ha llevado a incorporar en la ley concursal -Insolvency Act de 1986- la figura del wrongful trading, contemplada en la Sec. 214. Por esta vía, el legislador estableció un estándar objetivo de diligencia de los administradores dirigentes (esto es, los que dirigen los negocios de la sociedad, por oposición a los que no lo hacen), exigible tanto al administrador de derecho (Sec. 251) como también al de hecho o "shadow director" (Sec. 215), sin necesidad de acreditar necesariamente un propósito fraudulento. La figura no alcanza en todo caso a imponer responsabilidad al shadow o de facto director, pero faculta al juez para exigirle una contribución suficiente como para equilibrar los activos realizables y los pasivos exigibles de la sociedad controlada en insolvencia. Sobre el particular puede consultarse a PrEnTICE (1991) pp. 77-79.
} 
1. ¿Debe hacerse extensiva la quiebra de la sociedad dominada a la sociedad dominante como administradora de hecho?

La nueva LRL deroga la LQ y elimina con ella el art. 51, que contemplaba la figura de la extensión de la quiebra en una versión originaria, propia del derecho estatutario medieval. Sin perjuicio de ello, la figura se conserva aún en algunos ordenamientos concursales como el argentino, aunque con un sentido muy diverso y con miras a sancionar el ejercicio abusivo de la administración de hecho o de derecho y la confusión patrimonial inescindible en caso de insolvencia. Su eventual implementación en el derecho chileno, sin embargo, nos parece inconveniente por cuanto por esa vía se afecta el derecho de prenda general de los acreedores de la sociedad matriz y se somete a un régimen concursal de excepción a personas que no se encuentran en cesación de pagos, con el consiguiente perjuicio para sus accionistas - principalmente los minoritarios-, trabajadores y acreedores.

2. Alternativamente; ¿debe establecerse un régimen de responsabilidad civil o patrimonial que afecte a los administradores que han dirigido de hecho los negocios del fallido, provocando o agravando su estado de cesación de pagos?

La ley concursal chilena no contempla mecanismos legales ajustados a la dinámica grupal, diseñados para hacer efectiva la responsabilidad de la sociedad dominante que, con abuso de la dirección unitaria que actúa, causa, agrava o prolonga la insolvencia de una dominada del mismo grupo. La LRL, si bien avanza en este punto respecto de la derogada LQ al posponer los créditos relacionados y al incluir un nuevo tipo penal que reconoce la figura del administrador de hecho (art. 463 quáter del Código Penal), lo hace sin embargo de manera incompleta -y acaso ineficiente- al no regular la responsabilidad civil autónoma por el déficit concursal en estos casos, con las consecuencias ya expuestas en el texto. Por ese camino, desde luego, resultará imposible acceder al patrimonio de la sociedad madre, que obviamente no puede considerarse como sujeto activo del delito referido.

Considerando que la LRL elimina también la obligación del art. 41 de la LQ, orientada a provocar la declaración temprana de la quiebra a solicitud del propio deudor (mecanismo también ineficaz como lo ha demostrado la práctica, al vincularse básicamente con un tipo penal), resulta necesario incorporar una acción directa de responsabilidad civil en contra del administrador de hecho, que permita estimular la declaración temprana recién mencionada y salvar además el déficit del concurso de la sociedad controlada del grupo, como ocurre en las legislaciones española y uruguaya puestas como ejemplo.

La regulación de este estatuto especial de responsabilidad, con todo, debe ir acompañada de un régimen también diferenciado en cuanto a la prueba y a quién debe asumir su carga. Teniendo en cuenta las dificultades que tendrá en este caso el acreedor demandante o el liquidador del concurso de la dominada para acceder a la información económica, financiera y contable de la matriz (que por cierto no se encuentra declarada en concurso), consideramos que dicha carga probatoria deberá recaer en el administrador de hecho cuyos deberes de lealtad, diligencia y cuidado, en cuanto obligaciones aplicables a todo administrador, resulten controvertidos. Dicho de otra forma, la sola constatación de la existencia del grupo permite presumir iuris tantum, en ciertas ocasiones y con determinados límites, la responsabilidad del controlador, de quien es dable esperar un estándar objetivo de dili- 
gencia mínima al momento de diseñar e impartir sus directrices a las filiales del grupo y, particularmente, a la deviene en insolvente.

3. ¿Debe establecerse algún mecanismo legal diferenciado de responsabilidad del administrador de la sociedad dominada declarada en quiebra (o en liquidación), que ha actuado bajo instrucciones y por imposición de la dominante? O planteado de otra forma; ¿supone la extensión de responsabilidad al administrador de hecho una exoneración correlativa de responsabilidad del administrador de derecho por la insolvencia judicialmente declarada de la sociedad dominada?

Los administradores de derecho de la sociedad dominada, que deviene en insolvente por las directrices dañosas de la matriz del grupo, serán responsables frente a la sociedad y sus accionistas con sujeción al régimen aplicable a las sociedades-isla y, en todo caso, solo en la medida que infrinjan sus deberes fiduciarios, ejecutando las referidas instrucciones sin que exista una razón de negocio que las justifique de cara al interés de la sociedad que administran. La dinámica del grupo, por lo demás, implica que en algunas ocasiones esos administradores no cuentan con las herramientas de juicio suficientes para definir el real estado financiero de la sociedad, que solo conoce la dominante, lo que debe ser analizado en cada caso particular.

\section{BIBLIOGRAFÍA CITADA}

Antunes, José Engrácia (1994): Liability of Corporate Group: Autonomy and Control in Parent-Subsidiary Relationships in US, German and E.U. Law. An International and Comparative Perspective, Deventer - Boston, Kluwer Law and Taxation Publishers.

Bonelli, Franco (1985): Gli amministratore di società per azioni (Milán, Giuffrè).

Embid Irujo, José Miguel (2010): Ley alemana de sociedades anónimas (Madrid, Marcial Pons).

Fuentes Naharro, Mónica (2007): Grupos de sociedades y protección de acreedores (una perspectiva societaria) (Navarra, Thomson-Civitas).

Gebhardt, Marcelo (2009 Prevención de la insolvencia (Buenos Aires, Astrea).

Gonzalo López, Vicente (2001): La quiebra por extensión (Madrid, Consejo General del Notariado).

KÜBler, Friederich (2001): Derecho de Sociedades (trad. Michèle Klein, Madrid, Fundación Cultural del Notariado, quinta edición).

Miguens, Héctor José (2006): Extensión de la Quiebra y Responsabilidad en los Grupos de Sociedades (Buenos Aires, LexisNexis).

Moya Jiménez, Antonio (2012): La responsabilidad de los administradores de empresas insolventes, $8^{\mathrm{a}} \mathrm{ed}$. (Barcelona, Bosch).

Pariente, Maggy (1995): Les groupes des sociétés. Aspects juridique, social, comptable et fiscal (Paris, LexisNexis/Litec).

Puga Vial, Juan Esteban (2011): La Sociedad Anónima y otras sociedades por acciones en el derecho chileno y comparado (Santiago de Chile, Edit. Jurídica de Chile). 
Quatraro, Bartolomeo, Piconne, Luca G. (1998): La responsabilità di amministratori, sindaci, direttori generali e liquidatori di società: aspetti civili, penali e tributari (Milano, Giuffrè).

\section{OBRAS COLECTIVAS}

Abbadessa, Pietro (1982): “I gruppi di società nel diritto italiano", en Pavone La Rosa (dir.), I gruppi di società (Bolonia, Il Mulino).

Cerdá Albero, Alberto (2005): "La insolvencia: presupuesto objetivo del concurso", en Estudios sobre la Ley Concursal, libro homenaje a Manuel Olivencia, Tomo 1 (Madrid, Marcial Pons).

KRIEGER, Georg (1999): “Die rechtlichen Haftungsrisiken im konzern”, en Hoffmann-Becking (hrsg.), Münchener Handbuch des Gesselschaftrechts (München, Beck) Segunda edición.

López Rodríguez, Carlos (2012): "El accionista único como administrador de hecho en el derecho uruguayo", en Jequier Lehuedé, Eduardo (coord.), Cuadernos de Extensión Jurídica, No 22 (Santiago, Facultad de Derecho Universidad de los Andes) pp. 207-227.

LutTer, Marcus (1997): "Haftung aus Konzernvertrauen?", en W. Schön (dir.), Gedächtnisschrift für B. Knobbe Keuk, VV.AA. (Köln, Dr. Otto Schmidt) pp. 229-245.

Prentice, Dan D. (1991): "Group Indebtedness", en Schmmitthof, Clive y Wooldridge, Frank (eds.), Groups of companies (Londres, Sweet \& Maxwell).

Rojo Fernández-Río, Ángel (2003): "La reforma del derecho concursal español“, en Rojo FERNÁNDEZ-Río, Ángel (dir.) La reforma de la legislación concursal, Jornadas sobre la reforma de la legislación concursal (Madrid, Marcial Pons).

Sánchez Calero, Fernando (1991): "Supuestos de responsabilidad de los administradores de la SA", en Consejo General de los Colegios Oficiales de Corredores de Comercio (edit), Derecho mercantil de la Comunidad Económica Europea. Estudios en homenaje a José Girón Tena (Madrid, Civitas).

\section{REVISTAS Y PUBLICACIONES PERIÓDICAS}

JeQuier Lehuedé, Eduardo (2014): "Premisas para el tratamiento de los grupos empresariales y administradores de hecho en el derecho chileno", Revista Chilena de Derecho, vol. 41, $\mathrm{N}^{\circ}$ 1, enero-abril 2014: pp. 121-152.

Miguens, Héctor José (2000): “La responsabilidad patrimonial en los grupos de sociedades en el ámbito de la Unión Europea", Revista Díkaion, Universidad de La Sabana, Vol. 9.

Sánchez-Calero Guilarte, Juan (2005): "Algunas cuestiones concursales relativas a los grupos de sociedades", en Anuario de Derecho Concursal, No 5, pp. 7-60.

Sánchez-Calero Guilarte, Juan, Naharro Fuentes, Mónica (2012): "La reforma concursal y los grupos de sociedades", en Documentos de Trabajo del Departamento de Derecho Mercantil, N44, febrero de 2012 (Madrid, Universidad Complutense, Facultad de Derecho).

Sánchez-Calero, Fernando (1979): "Grupos de sociedades y mercado de valores", Boletín Financiero de la Bolsa de Barcelona, N 69. 
Teubner, Günther (1991): “Das Konzernrecht in der neuen Dezentralität der Unternehmensgruppen”, Zeitschrift für Unternehmens- und Gesellschaftsrecht, Unitas-Multiplex, año 20, $\mathrm{N}^{\circ} 2$, pp. 189-217.

Windbichler, Christine (2000): "Corporate Group Law for Europe, Comments on the Forum Europaeum's Principles and Proposals for a European Corporate Group Law", European Business Organization Law Review, vol.1: pp. 265-286.

\section{OTRAS PUBLICACIONES}

Foiguel Borci, Amelia (2013): "La ausencia de compensación como requisito adicional para la extensión de la quiebra a la controlante (art. 161, inc. 2 de la Ley No 24.522)”, en Revista Argentina de Derecho Concursal, IJ-LXIX-140. Disponible en http://www.ijeditores. com.ar/articulos.php?idarticulo=66140\&print=2. Consultado el 14 de mayo de 2014 .

López Rodríguez, Carlos (2014): Responsabilidad de los administradores de hecho por el déficit concursal. Estudio comparado del Derecho español, uruguayo y argentino, Tesis doctoral (Universitat de Valencia).

Rojo Fernández-Río, Ángel (2003): "La reforma del derecho concursal español“. Disponible en: http://portal.uam.es/portal/page/portal/UAM_ORGANIZATIVO/Departamentos/AreasDerecho/AreaDerechoMercantil/Investigaci\%F3n/Trabajos\%20y\%20WP/ Trabajos\%20y\%20Working\%20Papers/arfr\%20-\%20reforma\%20dconcursal.pdf. 